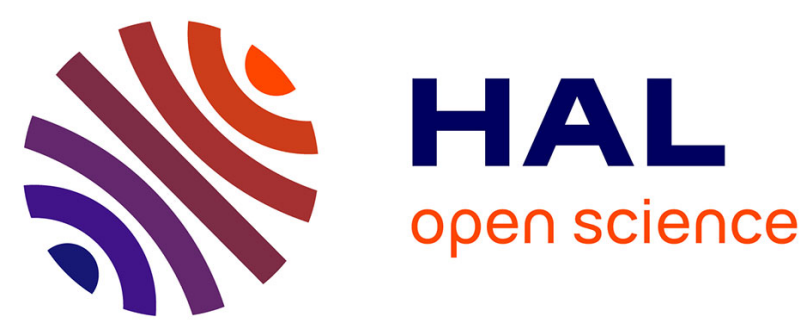

\title{
A quantitative study of the morphology of montmorillonite filled thermosets based on a tailor made homogenisation model
}

Melissa Poncet-Malige, Stéphane Corn, Aurélie Taguet, José-Marie

Lopez-Cuesta

\section{To cite this version:}

Melissa Poncet-Malige, Stéphane Corn, Aurélie Taguet, José-Marie Lopez-Cuesta. A quantitative study of the morphology of montmorillonite filled thermosets based on a tailor made homogenisation model. Composites Part A: Applied Science and Manufacturing, 2015, 77, pp.67-74. 10.1016/j.compositesa.2015.05.036 . hal-02914198

\section{HAL Id: hal-02914198 \\ https://hal.science/hal-02914198}

Submitted on 7 Jan 2021

HAL is a multi-disciplinary open access archive for the deposit and dissemination of scientific research documents, whether they are published or not. The documents may come from teaching and research institutions in France or abroad, or from public or private research centers.
L'archive ouverte pluridisciplinaire HAL, est destinée au dépôt et à la diffusion de documents scientifiques de niveau recherche, publiés ou non, émanant des établissements d'enseignement et de recherche français ou étrangers, des laboratoires publics ou privés. 


\title{
A quantitative study of the morphology of montmorillonite filled thermosets based on a tailor made homogenisation model
}

\author{
Mélissa Poncet-Malige, Stéphane Corn*, Aurélie Taguet, José-Marie Lopez-Cuesta \\ Centre des Matériaux des mines d'Alès, C2MA, École des mines d'Alès, 6 avenue de Clavières, F-30319 Alès Cedex, France
}

\begin{abstract}
A B S T R A C T
Thermoset/montmorillonite nanocomposites were fabricated and their elastic modulus was measured using experimental modal analysis. The morphology of the nanocomposite was considered as a distribution of several components: exfoliated clay platelets, intercalated clay layers, primary particles and clay agglomerates. A novel homogenisation model, which involves a five-phase sequence based on the Halpin-Tsai equations, was developed to calculate the elastic modulus of the nanocomposites. This model was then used to quantify the morphology of the nanocomposites by back calculating the exfoliation, intercalation and agglomeration fractions from the measured values of the elastic modulus. Additionally, this approach led to quantify the efficiency of the fabrication process, which proved to be optimal for $2.5 \%$ clay content.
\end{abstract}

Keywords:

A. Particle-reinforcement

B. Elasticity

C. Computational modelling

E. Thermosetting resin

\section{Introduction}

In recent years, nanoclays have attracted great interest in both academic and industrial research as they potentially permit a significant enhancement at low filler content [1]. Furthermore, they can exhibit added multifunctionality such as fire reaction, thermal stability and gas permeability barrier properties. For the last twenty years, layered silicate polymer nanocomposites have been specifically studied [1]. The most widely used layered silicates are based on montmorillonite, which is composed of extremely thin clay platelets that exhibit large surface areas and high aspect ratios. The elastic modulus of these platelets is very high compared to that of the polymer matrix. In order to obtain nanocomposites with enhanced properties compared to conventional composites, the natural montmorillonite has to be organically modified [2], for example by a quaternary ammonium salt bearing long carbon chains. Hence, the dispersion of the clay platelets is improved and exfoliated structures can occur. The reinforcement effect of silicate layers strongly depends on the degree of dispersion of the platelets and the structure of the nanocomposite [3-5]. Polymer/clay composites morphology can be divided into four categories [6]: conventional miscible composite, intercalated nanocomposite, exfoliated nanocomposite and partially intercalated and partially exfoliated nanocomposite. Generally, the

\footnotetext{
* Corresponding author.

E-mail address: Stephane.Corn@mines-ales.fr (S. Corn).
}

structure of clay/polymer nanocomposites is partially intercalated and partially exfoliated, with intercalated clusters and individual platelets randomly distributed in the matrix.

The development of nanocomposites requires a better understanding of the structure-properties relationship and the ability to make predictions using adapted micromechanical models. Continuum models provide a rapid assessment of the key factors that control the reinforcement and the mechanical properties of conventional particle-polymer composites. Among the existing models, Halpin-Tsai and Mori-Tanaka homogenisation schemes $[7,8]$ were used to evaluate the properties of nanocomposites [9]. The mechanical behaviour of polymer/clay 'ideal' nanocomposites (e.g. assuming the complete exfoliation of clay platelets, their uniform dispersion and a perfect bonding between the matrix and the particles) can be predicted rather well with these models. But, due to the inherent complexity of the 'real' nanocomposite structure, discrepancies occur. Therefore, it is necessary to adapt existing models in order to take into account a realistic morphology of the nanocomposite [10-13]. In this paper, the reinforcing effect of an organomodified montmorillonite dispersed in a vinyl ester matrix is studied and a new micromechanical model, based on the Halpin-Tsai equations, is proposed to calculate the Young's modulus of polymer/layered silicate nanocomposites. Finally, by updating the morphological parameters of the model to match the experimental values of the elastic modulus, this new homogenisation scheme is used to predict the microstructure of the nanocomposites. 


\section{Experimental characterisation}

\subsection{Materials}

Ashland Derakane ${ }^{\circledR}$ Momentum ${ }^{\mathrm{TM}}$ 411-350 vinyl ester resin was used as the matrix. The clay material used was Cloisite ${ }^{\circledR}$ 30B supplied from Southern Clay Products. It is a natural montmorillonite mineral modified with methyl tallow bis-2-hydroxyethyl quaternary ammonium salt. The montmorillonite particles are disk-shaped stacks of thin silicate layers with a diameter ranging from $100 \mathrm{~nm}$ to several micrometres. Cloisite ${ }^{\circledR} 30 \mathrm{~B}$ typical physical properties are the following: a layer spacing of $1.85 \mathrm{~nm}$ and a specific gravity of 1.98 for the clay particles and of 2.6 for an individual layer.

\subsection{Processing}

Five compositions of nanocomposites, containing the montmorillonite weight fraction of $0,1.25,2.5,3.75$ and $5 \mathrm{wt} \%$, were performed in this study. Suspensions of organomodified clay in resin were manually stirred for $5 \mathrm{~min}$, then mechanically stirred with a VELP stirrer model LH, followed by ultrasonic mixing with a Branson digital sonifier ${ }^{\circledR}$ S-450D. The optimised process parameters used are given in Table 1 . The catalyst system used was $1.5 \mathrm{phr}^{1}$ of methyl ethyl ketone peroxide and $0.30 \mathrm{phr}$ of cobalt naphthenate (3\% in styrene). Mixtures were cast into silicone moulds to form blocks of $240 \mathrm{~mm} \times 40 \mathrm{~mm} \times 6 \mathrm{~mm}$. The blocks samples were then cured for $3 \mathrm{~h}$ at $80^{\circ} \mathrm{C}$.

\subsection{Morphology}

The structure of the nanocomposites was characterised by X-ray diffraction (Bruker AXS D8 ADVANCE) and scanning electron microscopy (Hitashi S-4300 ESEM). The d-spacing was obtained from X-ray diffraction. Cryo-fractured pieces of test specimens and cryo-microtomes of test specimens were used as SEM samples. Suspensions of organomodified clay in resin, filled in a hollowed specimen holder, were used for the X-ray diffraction analysis.

\subsection{Elastic parameters measurement set-up}

An experimental vibration technique called 'modal analysis' was used to determine the viscoelastic parameters (elastic modulus, and loss tangent not presented here) of the nanocomposite materials. The set-up simulates free boundary conditions by supporting the sample with soft suspensions [14]. The sample, a solid block, is excited in free vibration by an impulse hammer and its response is monitored by an accelerometer. The excitation and response are fed into the Fast Fourier Transform (FFT) analyser which computes and displays the frequency response curve. The natural frequencies of the sample are given by the series of peaks in the frequency response curve. The software MODAN, ${ }^{2}$ developed by the FEMTO-ST laboratory, from University of Franche-Comte, was used to extract natural frequencies and damping ratios from the frequency response function. Finite element model of each sample was correlated with the modal analysis results to identify the Young's modulus and Poisson's ratio of the materials. The samples used for modal analysis were parallelepipedic specimens with dimensions being $(240 \pm 0.5) \mathrm{mm} \times(40 \pm 0.5) \mathrm{mm} \times(6 \pm 0.02) \mathrm{mm}$. The accurate dimensions of each sample were updated in the finite element model used to calculate the elastic modulus. The elastic measurement were conducted at room temperature $\left(23^{\circ} \mathrm{C}\right)$.

\footnotetext{
1 Parts per hundred resin moulding compound.

2 Pr. Emmanuel Foltête - ENSMM, Département de Mécanique Appliquée - 24 chemin de l'Épitaphe - 25000 Besançon, France.
}

Table 1

Parameters of the mechanical stirring and of the ultrasonic mixing.

\begin{tabular}{llllll}
\hline \multirow{2}{*}{ Weight fraction (\%) } & \multicolumn{2}{l}{ Mechanical stirring } & & \multicolumn{2}{l}{ Ultrasonic mixing } \\
\cline { 2 - 3 } \cline { 5 - 6 } \cline { 5 - 6 } & Speed $(\mathrm{rpm})$ & Time $(\mathrm{min})$ & & Power $(\mathrm{W})$ & Time $(\mathrm{min})$ \\
\hline 1.25 & 1200 & 60 & & 72 & 30 \\
2.5 & 1500 & 60 & & 72 & 45 \\
3.75 & 1500 & 90 & & 80 & 45 \\
5 & 1500 & 120 & & 80 & 60 \\
\hline
\end{tabular}

\section{Results and modelling}

\subsection{Morphology}

As shown in Figs. 1 and 2, the nanocomposite materials contain montmorillonite primary particles with a layer-spacing of $1.82 \mathrm{~nm}$ (which is very close to the supplied data), and montmorillonite intercalated particles with a layer-spacing of $3.81 \mathrm{~nm}$. Moreover, agglomerates of montmorillonite were found in all the studied formulations (Figs. 3 and 4).

\subsection{Modelling procedure}

The whole structure of a polymer/clay nanocomposite is generally described as partially intercalated and partially exfoliated, but as seen with the morphological characterisation, the structure of the nanocomposite materials in this study also contains primary particles, with a layer-spacing of $1.82 \mathrm{~nm}$, and clay agglomerates. The structure of the nanocomposites is represented by a five-phase model, including the thermosetting matrix, exfoliated clay platelets, intercalated clay layers, primary particles and clay agglomerates. The proposed model is adapted from the work of Luo and Daniel [10].

\subsubsection{Assumptions of the model}

The matrix and the filler are assumed to exhibit linearly elastic and isotropic behaviour and to be firmly bonded. Platelets are assumed to be disks of diameter $L$ and thickness $d_{s}$ (Fig. 5a). It is assumed that a primary particle (Fig. 5 b) is a stack of $N_{0}$ non intercalated silicate layers, with a layer spacing $d_{0}=1.82 \mathrm{~nm}$. It is assumed that an intercalated particle (Fig. 5c) is a stack of $N$ intercalated silicate layers, with an interlayer spacing $d_{001}=3.81 \mathrm{~nm}$. And finally it is assumed that a montmorillonite agglomerate (Figs. 5d and 4) is a spherical cluster of primary particles. The exfoliated platelets, primary particles, intercalated particles and clusters of montmorillonite are assumed to be homogeneously distributed and randomly oriented in the matrix. For the exfoliated platelets, primary and intercalated particles, the axes parallel to the platelets are named the parallel $\|$ directions and the axis perpendicular to the platelets is named the transverse $\perp$ direction (cf. Fig. 5a). The model built in this study is based on the distribution of montmorillonite platelets given in Fig. 6: the clay volume fraction $\phi_{r}$ is divided into a volume fraction $\phi_{e}$ of exfoliated platelets, characterised by the exfoliation fraction $f_{e}$, and a volume fraction $\phi_{n e}$ of non exfoliated particles. The volume fraction of non exfoliated particles is divided into a volume fraction $\phi_{p i}$ of intercalated particles and a volume fraction $\phi_{p p}$ of primary particles and the intercalation fraction of non exfoliated clay particles is noted $f_{i}$. The volume fraction of primary particles is divided into a volume fraction $\phi_{p p n a}$ of non agglomerated primary particles and a volume fraction $\phi_{p p a}$ of agglomerated primary particles and the agglomeration fraction of the primary particles is noted $f_{a}$. 


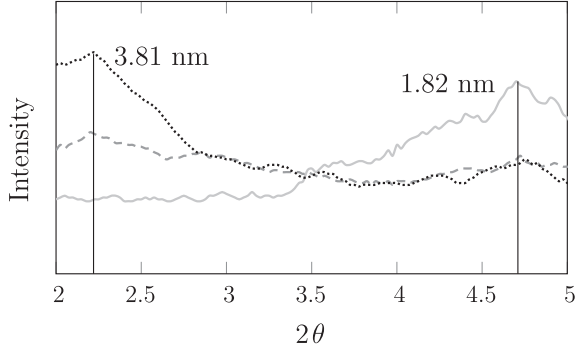

(a) Montmorillonite weight fraction: $2.5 \%$.

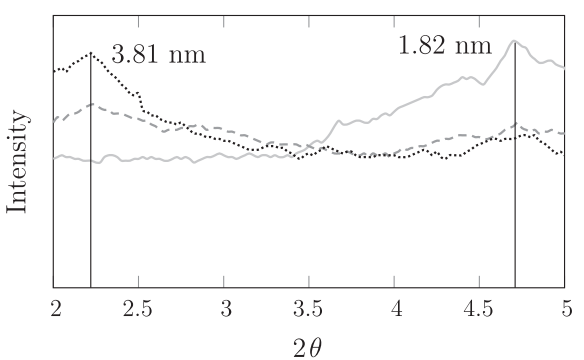

(b) Montmorillonite weight fraction: $5.0 \%$.

Fig. 1. X-ray diffractograms: —_ manual mixing --- - mechanical stirring; $\cdots$ ultrasonic mixing.

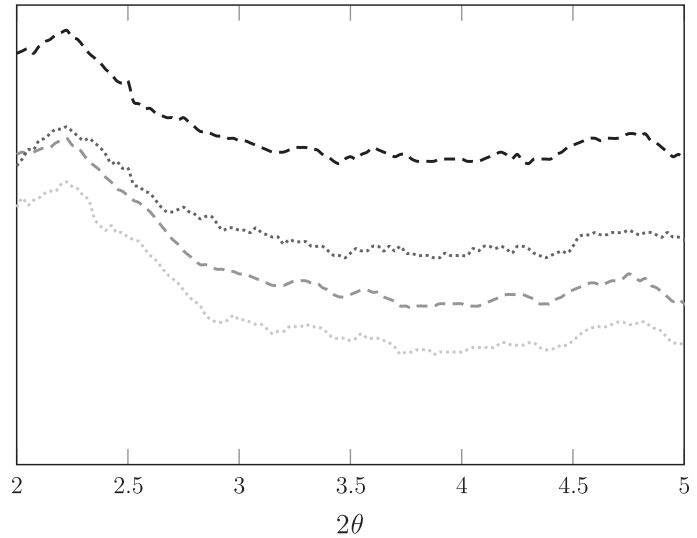

Fig. 2. X-ray diffractograms after ultrasonic mixing for different montmorillonite weight fractions: …....... $1.25 \%---2.5 \%+3.75 \%---5 \%$.

\subsubsection{Building of the homogenisation model}

The elastic modulus $E$ of a nanocomposite consisting of a matrix and platelet-like fillers with a completely three-dimensional random orientation and homogenous distribution can be, using the laminated model [15], calculated as:

$E=0.49 E_{\|}+0.51 E_{\perp}$

where $E_{\perp}$ and $E_{\|}$are the composite moduli perpendicular (transverse) and parallel to the major axis of the filler, respectively. The Eq. (1) [9] is an approximation proposed by van Es et al. using laminates theory $[16,17]$. The composite elastic modulus perpendicular to the filler major axis, $E_{\perp}$, and the composite elastic modulus parallel to the filler major axis, $E_{\|}$, can be calculated using Halpin-Tsai equations:

$E_{\perp}=\frac{1+\zeta_{\perp} \eta_{\perp} \phi_{f}}{1-\eta_{\perp} \phi_{f}} E_{m} \quad E_{\|}=\frac{1+\zeta_{\|} \eta_{\|} \phi_{f}}{1-\eta_{\|} \phi_{f}} E_{m}$

where $E_{m}$ is the elastic modulus of the matrix, $\phi_{f}$ is the volume fraction of filler and where the parameters $\eta_{\perp}$ and $\eta_{\|}$, in the directions perpendicular and parallel to the filler are given by the following equations:

$\eta_{\perp}=\frac{\frac{E_{f}}{E_{m}}-1}{\frac{E_{f}}{E_{m}}+\zeta_{\perp}} \quad \eta_{\|}=\frac{\frac{E_{f}}{E_{m}}-1}{\frac{E_{f}}{E_{m}}+\zeta_{\|}}$

where $E_{f}$ is the elastic modulus of the filler and where $\zeta_{\perp}$ and $\zeta_{\|}$are the shape parameter of the filler, in the directions transverse and parallel to the filler, respectively.

For a nanocomposite material containing more than one variety of filler, the modelling procedure becomes a multi-step approach. As the nanocomposite materials in this study contain exfoliated platelets, intercalated and primary particles as well as agglomerates (Fig. 5), the modelling procedure is divided in a 4 steps approach:

1. Halpin-Tsai model is applied to the matrix and to the exfoliated platelets to determine a parallel $\left(E_{1 \|}\right)$ and a transverse $\left(E_{1 \perp}\right)$ elastic moduli, then the equation proposed by van Es (cf. Eq. (1)is used to determine the elastic modulus $E_{1}$ of the first effective matrix.

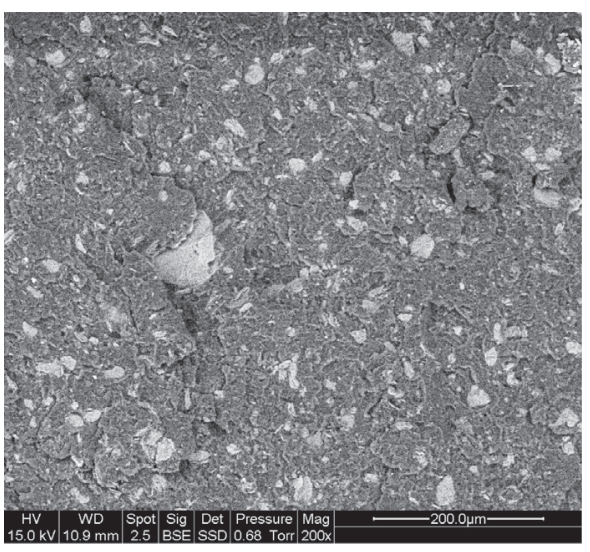

(a) Montmorillonite weight fraction: $2.5 \%$.

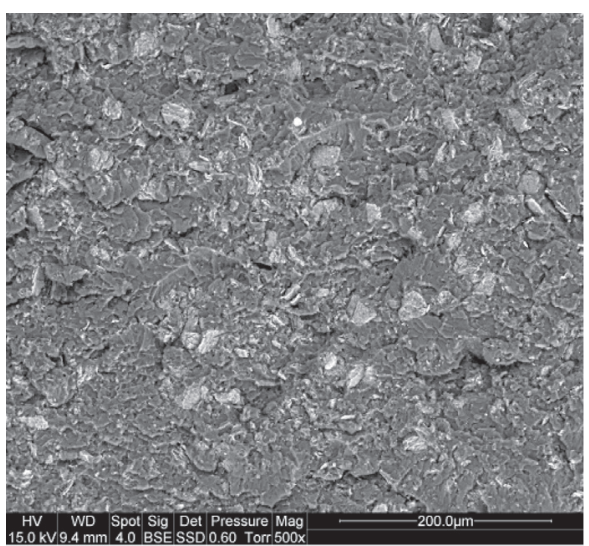

(b) Montmorillonite weight fraction: $5.0 \%$.

Fig. 3. Momentum ${ }^{\mathrm{TM}} 411-350 /$ Cloisite $^{\circledR} 30 \mathrm{~B}$ composites micrographs. 


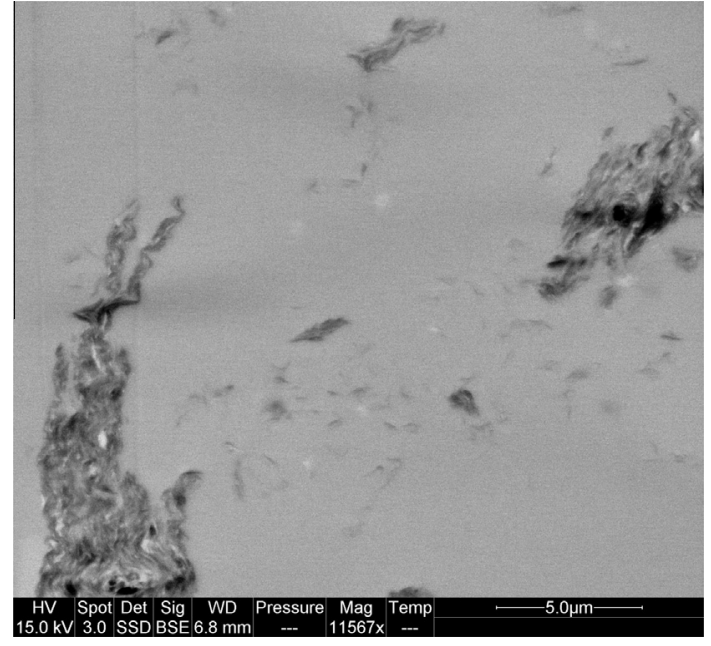

Fig. 4. Momentum ${ }^{\mathrm{TM}}$ 411-350/Cloisite ${ }^{\circledR}$ 30B composites STEM micrograph Montmorillonite weight fraction: $2.5 \%$.

2. The same principle is applied to the first effective matrix and to the effective intercalated particles, to determine the elastic modulus $E_{2}$ of the second effective matrix.

3. Then the same is done with the second effective matrix and the non agglomerated effective primary particles, to determine the elastic modulus $E_{3}$ of the third effective matrix.

4. Finally, one last repetition, with the third effective matrix and the agglomerated primary particles allows determining the elastic modulus $E_{c}$ of the nanocomposite.

For each step $i$ of the procedure, $i$ ranging from 1 to 4 , the elastic modulus $E_{i}$ is calculated using the following equations:

$E_{i}=0.49 E_{i \|}+0.51 E_{i \perp}$

$E_{i \|}=\frac{1+\eta_{i \|} \zeta_{i \|} \phi_{i}}{1-\eta_{i \|} \phi_{i}} E_{i-1} \quad E_{i \perp}=\frac{1+\eta_{i \perp} \zeta_{i \perp} \phi_{i}}{1-\eta_{i \perp} \phi_{i}} E_{i-1}$

$\eta_{i \|}=\frac{\frac{E_{f i}}{E_{i_{i}}-1}-1}{\frac{E_{f i}}{E_{i}-1}+\zeta_{i \|}} \quad \eta_{i \perp}=\frac{\frac{E_{f i}}{E_{i}-1}-1}{\frac{E_{f i}}{E_{i}-1}+\zeta_{i \perp}}$

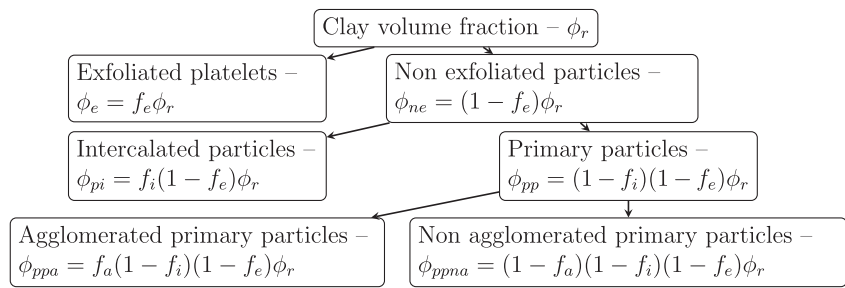

Fig. 6. Distribution of the montmorillonite platelets in the nanocomposites.

Table 2

Elastic moduli, shape parameters and volume fraction of the various fillers - $L$ is the diameter of a silicate platelet, and $d_{s}$ is its thickness.

\begin{tabular}{lllll}
\hline & $E_{f i}$ & $\zeta_{i \|}$ & $\zeta_{i \perp}$ & $\phi_{i}$ \\
\hline$i=1$ & $E_{r}$ & $2 \frac{L}{d_{s}}$ & 2 & $\phi_{e}$ \\
$i=2$ & $E_{p i}$ & $2 \frac{L}{(N-1) d_{001}+d_{s}}$ & 2 & $\phi_{2}=\frac{\phi_{p i}}{\phi_{p p i}}$ \\
$i=3$ & $E_{p p}$ & $2 \frac{L}{\left(N_{0}-1\right) d_{0}+d_{s}}$ & 2 & $\phi_{3}=\frac{\phi_{p p n a}}{\phi_{r p p}}$ \\
$i=4$ & $E_{a}$ & 2 & 2 & $\phi_{p p a}$ \\
\hline
\end{tabular}

with $E_{0}=E_{m}$, the elastic modulus of the matrix and $E_{4}=E_{c}$, the elastic modulus of the nanocomposite containing the four varieties of montmorillonite fillers. The volume fraction, shape parameters and elastic moduli of the different types of filler are given in Table 2.

The elastic modulus of an intercalated particle $E_{p i}$, with an interlayer spacing of $d_{001}$ and a number $N$ of silicate layers for each intercalated particle, is calculated by using the rule of mixtures, as proposed by Brune and Bicerano [18]:

$E_{p i}=\phi_{r p i} E_{r}+\left(1-\phi_{r p i}\right) E_{m}$

where $\phi_{r p i}$, the volume fraction of silicate in an intercalated particle (cf. Fig. 5b), is the ratio of the volume of silicate in an intercalated particle to the total volume of an intercalated particle, and is given by the following equation:

$\phi_{r p i}=\frac{N d_{s}}{(N-1) d_{001}+d_{s}}$

and the elastic modulus of an effective primary particle $E_{p p}$, with an interlayer spacing of $d_{0}$ and a number $N_{0}$ of silicate layers for each primary particle, is calculated using:

$E_{p p}=\phi_{r p p} E_{r}$

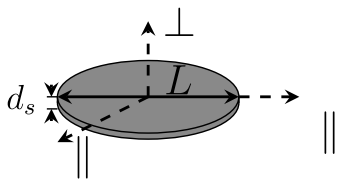

(a) Disk-like platelet.

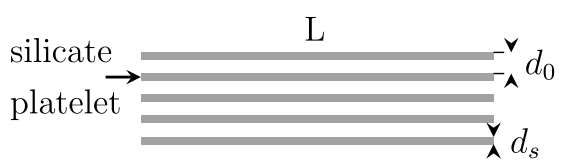

(b) Primary particle.

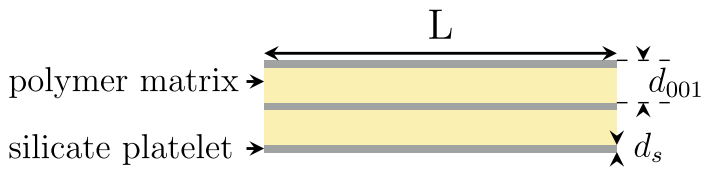

(c) Intercalated particle

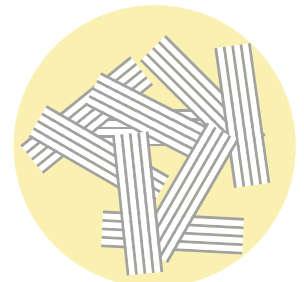

(d) Agglomerate.

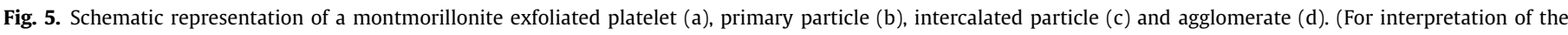
references to colour in this figure legend, the reader is referred to the web version of this article.) 
where $\phi_{r p p}$, the volume fraction of silicate in a primary particle (cf. Fig. $5 c$ ), is the ratio of the volume of silicate in a primary particle to the total volume of a primary particle, and is given by the following equation:

$\phi_{r p p}=\frac{N_{0} d_{s}}{\left(N_{0}-1\right) d_{0}+d_{s}}$

$\phi_{2}$, the effective volume fraction of intercalated particles, is given by:

$\phi_{2}=\frac{\phi_{p i}}{\phi_{r p i}}=\frac{f_{i}\left(1-f_{e}\right) \phi_{r}}{\phi_{r p i}}$

and $\phi_{3}$, the volume fraction of primary particles, is given by:

$\phi_{3}=\frac{\phi_{p p n a}}{\phi_{r p p}}=\frac{\left(1-f_{a}\right)\left(1-f_{i}\right)\left(1-f_{e}\right) \phi_{r}}{\phi_{r p p}}$

The explanation for the expression and values of $\zeta_{i \|}$ and $\zeta_{i \perp}$ are given elsewhere [19,9].

\subsection{Values of the input parameters of the model}

The homogenisation model described above uses several input parameters, whose values are discussed below.

Numbers $N_{0}$ and $N$ of platelets - Considering that the thickness of a montmorillonite particle is substantially constant and of the order of 8 to $10 \mathrm{~nm} \mathrm{[20]} \mathrm{(when} \mathrm{the} \mathrm{interlayer} \mathrm{distance}$ increases, the number of silicate platelets per stack decreases), the average number $N_{0}$ of platelets per stack in a primary particle can be estimated by the following equation ${ }^{3}$ :

$$
\left\lfloor\frac{8-d_{s}}{d_{0}}+1\right\rfloor \leqslant N_{0} \leqslant\left\lceil\frac{10-d_{s}}{d_{0}}+1\right\rceil
$$

where $d_{s}$ is the thickness (in $\mathrm{nm}$ ) of a silicate platelet and where $d_{0}$ is the interlayer distance (in $\mathrm{nm}$ ) in a montmorillonite primary particle. Thus, here, a primary particle is formed of an average stack of 5.4 platelets.

In the same way, the average number $N$ of platelets per stack in an intercalated particle, with an interlayer distance of $d_{001}$ can be estimated by the following equation:

$$
\left\lfloor\frac{8-d_{s}}{d_{001}}+1\right\rfloor \leqslant N \leqslant\left\lceil\frac{10-d_{s}}{d_{001}}+1\right\rceil
$$

Thus, here, an intercalated particle is formed of an average stack $N$ of 3 platelets.

Thickness $d_{s}$ of a silicate platelet - From the data of Fornes and Paul [9], the thickness $d_{s}$ of a single platelet of montmorillonite is considered to be $0.94 \mathrm{~nm}$.

Elastic modulus $E_{r}$ of a single silicate platelet - Chen and Evans [21] have established that the elastic modulus of smectite clay platelets is between 178 and $265 \mathrm{GPa}$. For this study, an average value of $220 \mathrm{GPa}$ was used for $E_{r}$, the elastic modulus of a single montmorillonite platelet.

Elastic modulus $E_{a}$ of a clay agglomerate - The elastic modulus of a clay agglomerate $E_{a}$ can be estimated at $50 \mathrm{GPa}$ [21].

Elastic modulus $E_{m}$ of the thermoset matrix - The elastic modulus of the vinyl ester matrix is $3.22 \mathrm{GPa} \pm 0.05 \mathrm{GPa}$ (determined by modal analysis, cf. Table 3 ).

Width $L$ of a silicate platelet - The values of $L$ given in the literature often extend between 100 and $200 \mathrm{~nm}$ [9,22]. In the following, the value of $L$ used is $150 \mathrm{~nm}$.

\footnotetext{
$\left.{ }^{3} \downarrow\right\rfloor$ and $\lceil 7$ representing the floor and ceiling functions.
}

Table 3

Experimental results of the elastic modulus and standard deviation (GPa).

\begin{tabular}{ll}
\hline Weight fraction $(\%)$ & Elastic modulus $(\mathrm{GPa})$ \\
\hline 0 & $3.22 \pm 0.05$ \\
1.25 & $3.52 \pm 0.05$ \\
2.5 & $3.85 \pm 0.05$ \\
3.75 & $3.90 \pm 0.05$ \\
5 & $3.97 \pm 0.05$
\end{tabular}

Exfoliation fraction $f_{e}$ - Following the example of Luo and Daniel [10], if uniform dispersion and random orientation of the filler are assumed, an upper limit to the exfoliated volume fraction $\phi_{e}$ can be estimated by the ratio of the volume of an exfoliated platelet to the cube of its largest dimension (Eq. (15)).

$$
\phi_{e}=f_{e} \phi_{r} \leqslant \frac{\pi d_{s}}{4 L}
$$

Thus the maximum exfoliation fraction $f_{e \text { max 3D }}$, defined as the upper limit of the exfoliation fraction is given by Eq. (16).

$$
f_{e \max 3 \mathrm{D}}=\frac{\pi d_{s}}{4 L \phi_{r}}
$$

Thereafter, the exfoliation fraction of the nanocomposite is restricted by this upper limit.

Intercalation and agglomeration fractions - The intercalation fraction $f_{i}$ of non exfoliated montmorillonite particles and the agglomeration fraction $f_{a}$ of the primary particles, can theoretically vary between 0 and 1 .

\subsection{Experimental results}

The elastic moduli of the montmorillonite reinforced nanocomposites, measured by experimental modal analysis, are listed in the Table 3.

The addition of $2.5 \%$ weight fraction of montmorillonite increases the elastic modulus of the matrix of about $20 \%$ whereas the addition of $5 \%$ weight fraction of montmorillonite increases the elastic modulus of the matrix of about $23 \%$. The increase of the elastic modulus of a thermosetting matrix by the addition of montmorillonite is an expected result already observed in the literature, with the intensity of the increase varying according to the nature of the materials used and the manufacturing process. For example, using montmorillonite with a silane treatment as a filler in an unsaturated polyester matrix, Kornmann et al. [23] observed an increase of $28 \%$ in the elastic modulus, for a montmorillonite concentration of $5 \mathrm{wt} \%$. With the same matrix and Cloisite ${ }^{\circledR} 30 \mathrm{~B}$ montmorillonite, Inceoglu and Yilmazer [24] obtained a $17 \%$ increase of the elastic modulus, for a montmorillonite concentration of $5 \mathrm{wt} \%$. With the same organomodified montmorillonite and an epoxy matrix, Yasmin et al. [25] obtained an increase of $18 \%$ of the elastic modulus, for a clay concentration of $5 \mathrm{wt} \%$, whereas with another organomodified montmorillonite (Nanomer ${ }^{\circledR}$ I.28E), the increase in the elastic modulus reached $25 \%$, for the same clay concentration.

\subsection{Comparison between model predictions and experimental results}

The five-phase model developed allows determining the elastic modulus of the composite $\left(E_{c}\right)$ by varying the morphology and especially the distribution of the montmorillonite platelets in the composite (cf. Figs. 5 and 6). Two extreme cases can be described: the most unfavourable one where the platelets are poorly exfoliated, and the most favourable one where the platelets are highly exfoliated. 
- In the most unfavourable composite the montmorillonite filler is uniformly dispersed in the matrix as clay agglomerates. The theoretical minimal elastic modulus $E_{\mathrm{mod}}^{\mathrm{min}}$ of such a composite is defined as the elastic modulus of a composite with a zero exfoliation fraction, a zero intercalation fraction of non exfoliated particles, and with an agglomeration fraction of primary particles of $1\left(f_{e}=0, f_{i}=0, f_{a}=1\right)$. Hence the increase of the elastic modulus of the matrix is only due to the addition of uniformly dispersed montmorillonite agglomerates, with neither exfoliation nor intercalation.

- In the most favourable composite, consisting of a partially exfoliated and partially intercalated nanocomposite, the exfoliation fraction is equal to the upper limit of the exfoliation fraction as defined above and in which all the non exfoliated particles are intercalated, with an interlayer distance equal to $d_{001}$. The theoretical maximal elastic modulus $E_{\bmod }^{\max }$ of such a nanocomposite is defined as the elastic modulus of a nanocomposite with an exfoliation fraction $f_{e}$ equal to $f_{e} \max 3 \mathrm{D}$, an intercalation fraction of non exfoliated particle $f_{i}$ of 1 , and with an agglomeration fraction of primary particles $f_{a}$ of 0 . Hence the increase in the elastic modulus of the matrix is due to the addition of uniformly dispersed montmorillonite, which shows the maximal exfoliation fraction that can be obtained, and to a complete intercalation of the remaining montmorillonite particle, without any agglomerates.

The theoretical minimal and theoretical maximal elastic moduli, estimated using the input parameters listed in Section 3.3, are shown in Fig. 7, together with the experimental data.

As expected for the nanocomposites of this study which present a morphology intermediary between these two extreme cases, the experimental values of the elastic modulus of the composites are between the theoretical minimum and maximum elastic moduli. Calculating the ratio of the experimental elastic modulus on the theoretical maximal elastic modulus (cf. Table 4) reveals that, for the lower levels of filler, the nanocomposite materials have an elastic modulus less than $10 \%$ lower than the theoretical maximal elastic modulus, which is a good result. The higher the filler weight fraction, the greater the difference between experimental and maximal values.

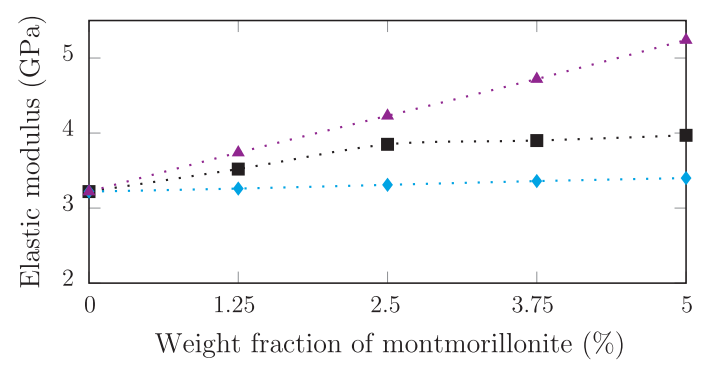

Fig. 7. - Theoretical minimal elastic modulus $E_{\mathrm{mod}}^{\min }, \ldots .$. . theoretical maximal elastic modulus $E_{\bmod }^{\max }$ and .. experimental data for several weight fractions of montmorillonite. (For interpretation of the references to colour in this figure legend, the reader is referred to the web version of this article.)

Table 4

Ratio of the experimental elastic modulus on the theoretical maximal elastic modulus.

\begin{tabular}{ll}
\hline Weight fraction (\%) & $\frac{E_{c}}{E_{\bmod }^{\max }}(\%)$ \\
\hline 1.25 & 93.9 \\
2.5 & 91.0 \\
3.75 & 82.6 \\
5 & 75.8 \\
\hline
\end{tabular}

The parameters involved in the increase of the elastic modulus of the nanocomposites that can be influenced by the fabrication process are the exfoliation, intercalation and agglomeration fractions.

The effective increase of the elastic modulus of the nanocomposite $R_{e}$ and the theoretical maximal increase in the elastic modulus of the nanocomposite $R_{\max }$ can be defined as:

$R_{e}=\frac{E_{c}-E_{\mathrm{mod}}^{\mathrm{min}}}{E_{\mathrm{mod}}^{\mathrm{min}}} \quad R_{\max }=\frac{E_{\mathrm{mod}}^{\mathrm{max}}-E_{\mathrm{mod}}^{\mathrm{min}}}{E_{\mathrm{mod}}^{\min }}$

In addition, as a mean to evaluate the efficiency $\Xi$ of the fabrication process in terms of exfoliation, intercalation and rupture of agglomerates, $\Xi$ is defined as the ratio of the effective increase in the elastic modulus of the nanocomposite $R_{e}$ on the theoretical maximal increase in the elastic modulus of the nanocomposite $R_{\max }$ :

$\Xi=\frac{R_{e}}{R_{\max }}=\frac{E_{c}-E_{\bmod }^{\min }}{E_{\bmod }^{\max }-E_{\bmod }^{\min }}$

The effective increase $R_{e}$ and the theoretical maximal increase in the elastic modulus of the nanocomposite $R_{\max }$, together with the efficiency $\Xi$ of the fabrication process in terms of exfoliation, intercalation and rupture of agglomerates are shown Fig. 8.

The efficiency of the fabrication process in terms of exfoliation, intercalation and rupture of agglomerates reaches its maximum for a weight fraction of montmorillonite of $2.5 \%$, the effective increase in the elastic modulus is then approximately $59 \%$ of the theoretical maximum increase of the elastic modulus. For higher weight fractions of montmorillonite, it is very noticeable that the delamination efficiency decreases with the filler weight fraction hence confirming that the nanocomposite material processing was optimal for 2.5 weight fraction of montmorillonite and should be improved for higher contents. Indeed, the fabrication process described above was chosen because it can be easily transposable for industrial purposes. But, it is most efficient for low amounts of montmorillonite. When the amount of montmorillonite is increased the process efficiency is not sufficient to improve the dispersion.

\subsection{Morphology optimisation by back calculation of the exfoliation, intercalation and agglomeration fractions}

To better identify the weaknesses in the manufacturing process, exfoliation, intercalation and agglomeration fractions, for which

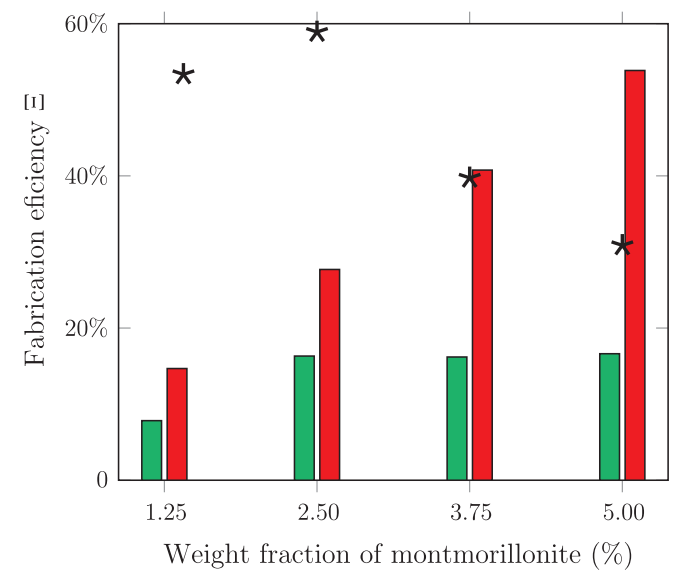

Fig. 8. $n$ Effective increase $R_{e}$ and $n$ theoretical maximal increase $R_{\max }$ in the elastic modulus of the nanocomposite. - $\star \star \star_{\star}$ Efficiency $\Xi$ of the fabrication process in terms of exfoliation, intercalation and rupture of agglomerates. (For interpretation of the references to colour in this figure legend, the reader is referred to the web version of this article.) 
the modelled elastic modulus is equal to the experimental elastic modulus, are back calculated using the modelling procedure described previously and the results are displayed in Fig. 9.

For a montmorillonite weight fraction of $1.25 \%$, the theoretical maximum exfoliation fraction $f_{e \text { max 3D }}$ is about 89\%. However, the maximum exfoliation fraction back calculated is only between $47 \%$ and $52 \%$, depending on the agglomeration fraction (cf. Fig. 9a), meaning that the maximum exfoliation fraction was not achieved during the processing of this nanocomposite whereas for the other compositions, the theoretical maximal exfoliation fraction $f_{e} \max$ 3D may have been reached. In addition, the intercalation fraction of non exfoliated particles reaches a maximum value of $63 \%$ for a montmorillonite weight fraction of $1.25 \%$ (cf. Fig. 9a), $66 \%$ for a montmorillonite weight fraction of $2.5 \%$ (cf. Fig. 9b), 43\% for a montmorillonite weight fraction of $3.75 \%$ (cf. Fig. 9c) and 33\% for a montmorillonite weight fraction of $5 \%$ (cf. Fig. 9d). Hence, a significant fraction of primary clay particles are not even intercalated. These results confirm that the higher the filler weight fraction, the lower the process efficiency in terms of intercalation. If the extend of the intercalation depends mainly on the type of organic treatment of the montmorillonite [26], intercalation fractions as high as $60-66 \%$ should also be achievable for the highest fractions of montmorillonite. Thus, in order to increase the elastic modulus of the nanocomposites, for the highest fractions of filler, their intercalation fraction should be increased to values ranging from $60 \%$ to $66 \%$, as it is already the case for the montmorillonite weight fraction of $2.5 \%$. If one considers that the exfoliation fraction is around $10 \%$, which is a reasonable assumption according to the literature [10], the possible ranges of the intercalation fraction are given in Table 5 .
Table 5

Possible ranges for the intercalation fraction $\left(f_{i}\right)$, for an exfoliation fraction of $10 \%$.

\begin{tabular}{lc}
\hline Weight fraction $(\%)$ & $f_{i}(\%)$ \\
\hline 1.25 & $51-56$ \\
2.5 & $53-59$ \\
3.75 & $25-34$ \\
5 & $12-23$ \\
\hline
\end{tabular}

Using an intercalation fraction of $60 \%$ and an exfoliation fraction of $10 \%$, the elastic moduli of the different composition have been estimated and are represented in Fig. 10. First, it is shown that, as expected, varying the agglomeration fraction do not change much the values of the elastic modulus. Moreover, for $1.25 \%$ and $2.5 \%$ weight fraction of montmorillonite, this distribution of the nanoclay $\left(f_{e}=10 \%\right.$ and $f_{i}=60 \%$ ) gives a value of the elastic modulus very close (cf. Fig. 10) to the one measured by modal analysis, demonstrating that the morphology of those two nanocomposites is probably well-described by the modified Halpin-Tsai model built. If one uses this distribution of the nanoclay for the highest fractions of montmorillonite (3.75\% and 5\%) however, huge discrepancies are found between estimated and measured values of the elastic modulus (cf. Fig. 10, Table 5). This result is to be expected as the highest intercalation fraction actually achieved is two to four times lower than $60 \%$, that is the intercalation fraction of $1.25 \%$ and $2.5 \%$ montmorillonite weight fraction nanocomposites (cf. Table 5). For the highest fractions of filler (5\%), an increase of the efficiency of the process in term of intercalation, from $30 \%$ (cf. Fig. 8) to 60\% (cf. Fig. 10) would lead to an increase in the elastic modulus of the matrix of $41 \%$ and $44 \%$, for an agglomeration

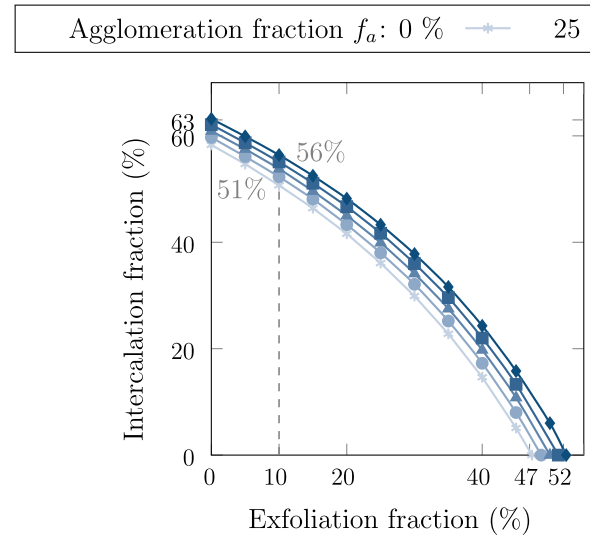

(a) $1.25 \mathrm{wt} \%$.

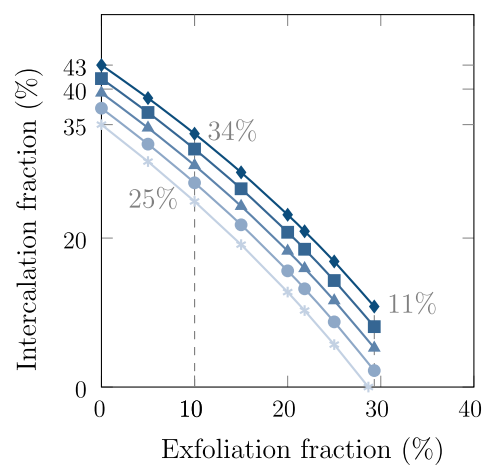

(c) $3.75 \mathrm{wt} \%$.

$25 \% \rightarrow 50 \% \rightarrow 75 \% \rightarrow-100 \% \rightarrow$

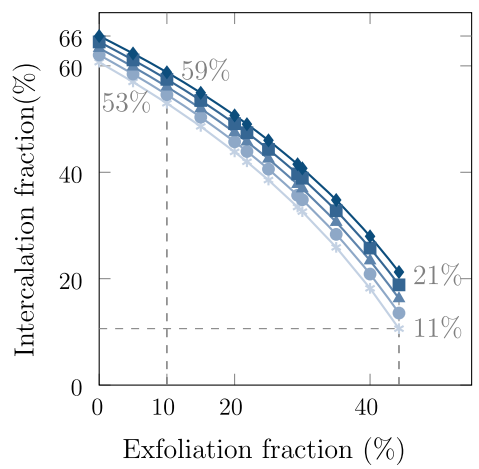

(b) $2.50 \mathrm{wt} \%$.

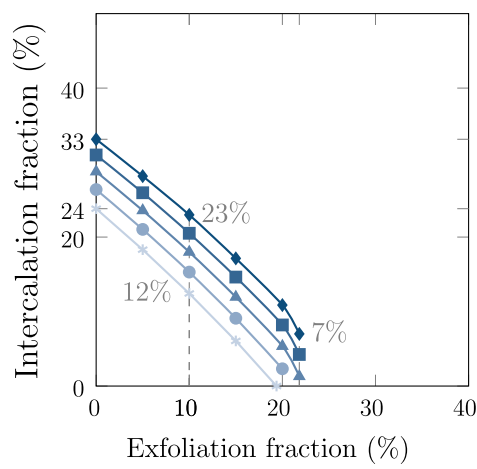

(d) $5.00 \mathrm{wt} \%$.

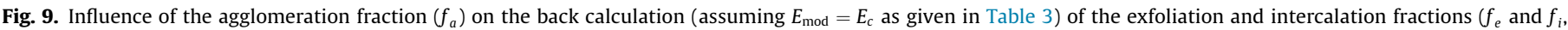

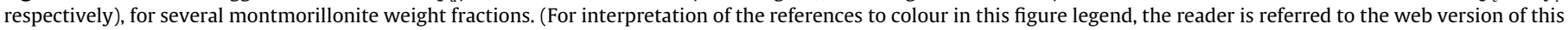
article.) 


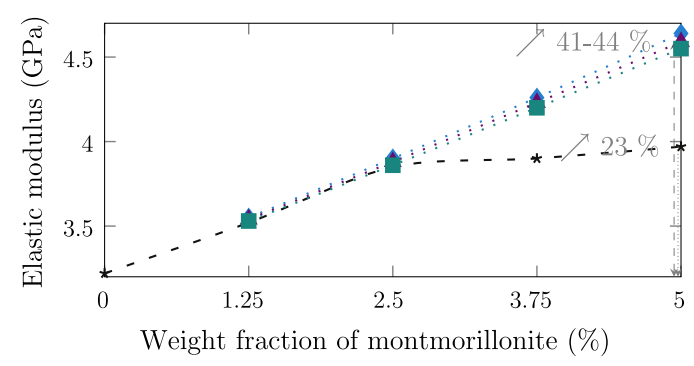

Fig. 10. - * Experimental elastic modulus and modelled elastic modulus for exfoliation fraction $\left(f_{e}\right)$ of $10 \%$ and intercalation fraction $\left(f_{i}\right)$ of $60 \%$ and for

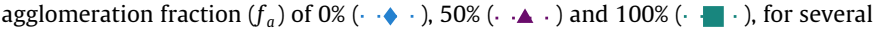
weight fraction of montmorillonite. (For interpretation of the references to colour in this figure legend, the reader is referred to the web version of this article.)

fraction of $100 \%$ and $0 \%$, respectively. By comparing these values of $41-44 \%$ to the value of $23 \%$ experimentally obtained for a montmorillonite weight fraction of 5\%, the increase in the elastic modulus that one would obtain with an intercalation fraction as high as $60 \%$ (the one obtained for a weight fraction of $2.5 \%$ ) can thus be estimated.

\section{Summary and conclusions}

In this work, thermoset/montmorillonite nanocomposites were studied. Besides the expected increase of the elastic modulus of the nanocomposites with the clay concentration, it was shown that the morphology of the nanocomposites filler could be effectively modelled as partially exfoliated and partially intercalated platelets, with the presence of non intercalated primary particles and clay agglomerates. A five-phase homogenisation model based on the Halpin-Tsai equations was developed to relate the elastic modulus of the materials to their morphology and to estimate the efficiency of the fabrication process in terms of exfoliation, intercalation and rupture of agglomerates. Moreover, this model was used to back calculate the exfoliation, intercalation and agglomeration fractions of the nanocomposite materials from the elastic modulus measured by an original modal analysis technique. Thereby, it was shown that with a limited exfoliation fraction (10\%), the intercalation fraction ranges from $12 \%$ (for $5 \%$ weight fraction of montmorillonite) to $59 \%$ (for $2.5 \%$ weight fraction of montmorillonite). The hypothesis of a distribution of montmorillonite platelets consisting of $10 \%$ of exfoliated platelets and $60 \%$ of intercalated particles was shown to be reliable for the $1.25 \%$ and $2.5 \%$ weight fractions of montmorillonite. Finally, this work was useful to describe a realistic distribution of montmorillonite particles assuming a limited exfoliation fraction.

\section{Acknowledgments}

We acknowledge both the Stiram Company (Montblanc, France) and ANRT (Agence Nationale pour la Recherche et la Technologie) for their financial support (these funding sources did not have any other involvement in this work).

\section{References}

[1] Sinha Ray S, Okamoto M. Polymer/layered silicate nanocomposites: a review from preparation to processing. Prog Polym Sci 2003;28(11):1539-641.

[2] Liu P. Polymer modified clay minerals: a review. Appl Clay Sci 2007;38(12):64-76.

[3] Százdi L, Pozsgay A, Pukánszky B. Factors and processes influencing the reinforcing effect of layered silicates in polymer nanocomposites. Eur Polymer J 2007;43(2):345-59.

[4] Ebadi-Dehaghani H, Khonakdar HA, Barikani M, Jafari SH. Experimental and theoretical analyses of mechanical properties of PP/PLA/clay nanocomposites. Compos Part B: Eng 2015;69:133-44.

[5] Hedayati A, Arefazar A. Study on dispersion and intercalation of organoclay in PP and PP-g-MA matrices. Polym Compos 2009;30(12):1717-31.

[6] LeBaron P, Wang Z, Pinnavaia T. Polymer-layered silicate nanocomposites: an overview. Appl Clay Sci 1999;15(1-2):11-29.

[7] Halpin JC, Kardos JL. The Halpin-Tsai equations: a review. Polym Eng Sci 1976;16(5):344-52.

[8] Mori T, Tanaka K. Average stress in matrix and average elastic energy of materials with misfitting inclusions. Acta Metall 1973;21(5):571-4.

[9] Fornes TD, Paul DR. Modeling properties of nylon 6/clay nanocomposites using composite theories. Polymer 2003;44(17):4993-5013.

[10] Luo J-J, Daniel IM. Characterization and modeling of mechanical behavior of polymer/clay nanocomposites. Compos Sci Technol 2003;63(11):1607-16.

[11] Zare-Shahabadi A, Shokuhfar A, Ebrahimi-Nejad S, Arjmand M, Termeh M. Modeling the stiffness of polymer/layered silicate nanocomposites: more accurate predictions with consideration of exfoliation ratio as a function of filler content. Polym Test 2011;30(4):408-14.

[12] Faraz M, Besseling N, Korobko A, Picken S. Structure-property relationships and modeling of the mechanical properties of a high-temperature resistant thermoset nanocomposite. Compos Part B: Eng 2014;56:9-14.

[13] Maksimov R, Gaidukovs S, Zicans J, Kalnins M, Plume E, Spacek V, et al. Nanocomposites based on a styrene-acrylate copolymer and organically modified montmorillonite 1. Mechanical properties. Mech Compos Mater 2006;42(3):263-72.

[14] Corn S, Dupuy J-S, Ienny P, Daridon L. Vibration analysis techniques for detecting filler-matrix decohesion in composites. Revue des Composites et des Matériaux Avancés 2012;22(1):77-90. <https://hal.archives-ouvertes.fr/hal00797606>.

[15] Yu Dong Y, Bhattacharyya D. Mapping the real micro/nanostructures for the prediction of elastic moduli of polypropylene/clay nanocomposites. Polymer 2010;51(3):816-24.

[16] van Es MA, Xiqiao F, van Turnhout J, van der Giessen E. Comparing polymerclay nanocomposites with conventional composites using composite modeling. In: Malaika S, Golovoy A, Wilkie CA, editors. Specialty polymer additives. Blackwell Publishing; 2001.

[17] Hull D, Clyne T. An introduction to composite materials. Cambridge solid state science series. Cambridge University Press; 1996.

[18] Brune DA, Bicerano J. Micromechanics of nanocomposites: comparison of tensile and compressive elastic moduli, and prediction of effects of incomplete exfoliation and imperfect alignment on modulus. Polymer 2002;43(2):369-87.

[19] Ashton JE, Halpin JC, Petit PH. Primer on composite materials: analysis. Technomic Publishing Co.; 1969.

[20] Le Pluart L, Duchet J, Sautereau H, Halley P, Gerard J-F. Rheological properties of organoclay suspensions in epoxy network precursors. Appl Clay Sci 2004;25(3-4):207-19.

[21] Chen B, Evans J. Elastic moduli of clay platelets. Scripta Mater 2006;54(9):1581-5.

[22] Sheng N, Boyce MC, Parks DM, Rutledge GC, Abes JI, Cohen RE. Multiscale micromechanical modeling of polymer/clay nanocomposites and the effective clay particle. Polymer 2004;45(2):487-506.

[23] Kornmann X, Berglund LA, Sterte J, Giannelis EP. Nanocomposites based on montmorillonite and unsaturated polyester. Polym Eng Sci 1998;38(8): $1351-7$.

[24] Inceoglu A, Yilmazer U. Synthesis and mechanical properties of unsaturated polyester based nanocomposites. Polym Eng Sci 2003;43(3):661-9.

[25] Yasmin A, Luo JJ, Abot JL, Daniel IM. Mechanical and thermal behavior of clay/ epoxy nanocomposites. Compos Sci Technol 2006;66(14):2415-22.

[26] Mironi-Harpaz I, Narkis M, Siegmann A. Nanocomposite systems based on unsaturated polyester and organo-clay. Polym Eng Sci 2005;45(2):174-86. 